\title{
IMPROVEMENT OF POWER QUALITY IN HVDC TRANSMISSION SYSTEMS WITH AUXILIARY CONVERTERS
}

\author{
J. B. Parizzi, F. A. Farret, A. B. Serdotte \\ Centro de Estudos em Energia e Meio Ambiente, Centro de Tecnologia, Universidade Federal de Santa Maria, \\ CEP 97105-900, Santa Maria - RS - Brasil \\ E-mails: parizzijb@gmail.com, faf@ct.ufsm.br, alvaroserdotte@gmail.com
}

\begin{abstract}
This paper intends to discuss some practical results of the reverse-use of the harmonic distortion energy from idle periods in conventional HVDC converters. It is shown that this energy can be used to reduce the total harmonic distortion, and so, the costs of harmonic filters, and to increase the power and utilization factors. The technique is based on the diversion of harmonic currents from a conventional HVDC converter to make it go through an auxiliary power converter with special features.
\end{abstract}

Keywords - energy re-cycling, harmonic minimization, HVDC transmission, high power converters, auxiliary converter, harmonic filters

\section{INTRODUCTION}

Quality of energy is a more and more relevant factor for minimized costs of electrical generation and transportation power systems. Strong points to be tackled are harmonic distortion and losses $[1,2]$. Such distortion and losses may be caused by circulation of currents at multiples of the fundamental frequency and by low power factors $[3,4,5]$, besides not having full usage of the available equipments.

When considering the use of HVDC converters one of the relevant factors is the current waveforms this equipment can impose on the AC system current. Use of passive and active filters and the increase of pulse number have been the conventional solution for that $[6,7,8,9]$. However, little has been said about use of and how to reduce the energy diverted from the harmonic filters in a more creative way.

From the above argument, this paper proposes the use of an auxiliary power converter in parallel with the main HVDC converter as a form of diverting its harmonic content to an auxiliary converter [3]. As a result of that it is expected to simultaneously minimize the energy of the overall harmonic content and to increase the utilization and power factors [3]. This second converter should take advantage of the available energy capacity within the idle periods of conventional HVDC converters: those are the periods between the phase voltage zero crossing instant and the valve firing instant [3].

The principle of reverse-use of energy from the idle periods of HVDC converters using auxiliary converters is illustrated in Figure 1. For the purposes of this paper, the $\mathrm{AC}$ source voltage and current waveforms may be divided

Manuscript received on 30/5/2006. Revised on 27/11/2006 and 3/9/2007. Accepted by recommendation of the Editor Richard. M. Stephan. into two portions: the first goes from the phase voltage zero crossing up to the thyristor firing instant and the second, goes from the firing instant to the next voltage zero crossing [3].

Two main aspects can be observed in this idea. The first refers to the reduced power demand from the auxiliary converter, because it will be using just the available energy of small firing angles that, usually in HVDC converters, are something in between $2^{\circ}$ to $20^{\circ}$. The second positive aspect is that this energy can be used for operation of auxiliary equipments, local consumption and/or re-injection back into the AC source under the same network frequency.

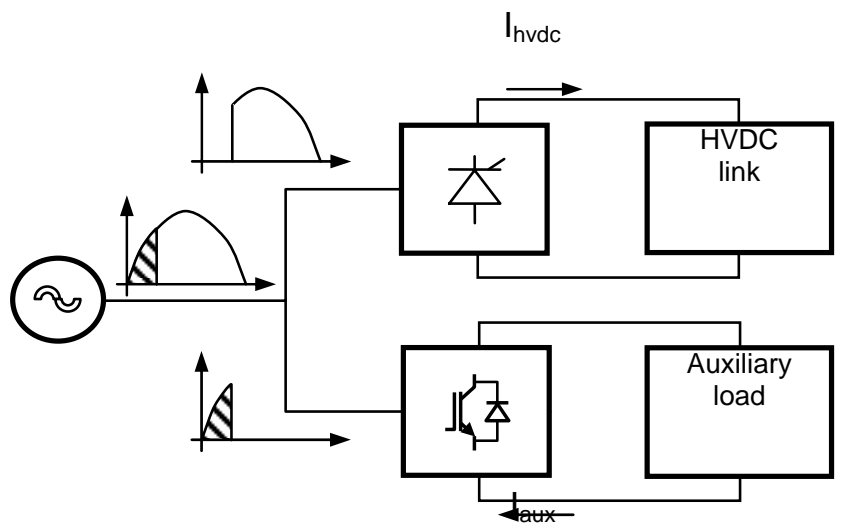

Fig. 1. Reverse-use of idle energy of HVDC converter

As it was already commented above, it is mostly relevant to consider the cost in any converter design. Therefore, to make worthy the addition of auxiliary converters as intended in this work, this one should be of relatively low cost and of easy implementation. As a compensation, it should be observed at this point that reduction of the harmonic content implicates into smaller harmonic filters and lower transmission cost in such a way that improvement in energy quality must compensate all investments. Furthermore, there will be global cost reduction and an improvement in the quality of the processed energy.

\section{USE OF AUXILIARY CONVERTER IN PARALLEL WITH A HVDC CONVERTER}

The proposed reverse-use of the energy from idle periods of HVDC converters is implemented as in Figure 2. Similar scheme was used either for the simulated and practical results. 
As it is known, the effects of the conduction angle over the power factor, come from the current delay caused by the firing angle $(\alpha)$ [2-10]. The auxiliary converter is activated during periods of time in which the HVDC converter is inoperative, in order to compensate its inherent inductive effect. In an ideal case, firing angles of up to $20^{\circ}$ are the most common case in HVDC converters. In other words, this interval goes in round terms from phase zero crossing to $30^{\circ}+\alpha$, neglecting all distortions. For $\alpha$ larger than or equal to $20^{\circ}$, the auxiliary converter should be activated along the phase voltage zero crossing to the firing instant given by $\alpha$. For instance, with $\alpha=5^{\circ}$ the auxiliary converter is activated between $0^{\circ}$ and $35^{\circ}$. By using this technique, besides approximating the main converter current waveshape to the sinusoidal form, it also improves the power and utilization factors and the THD.

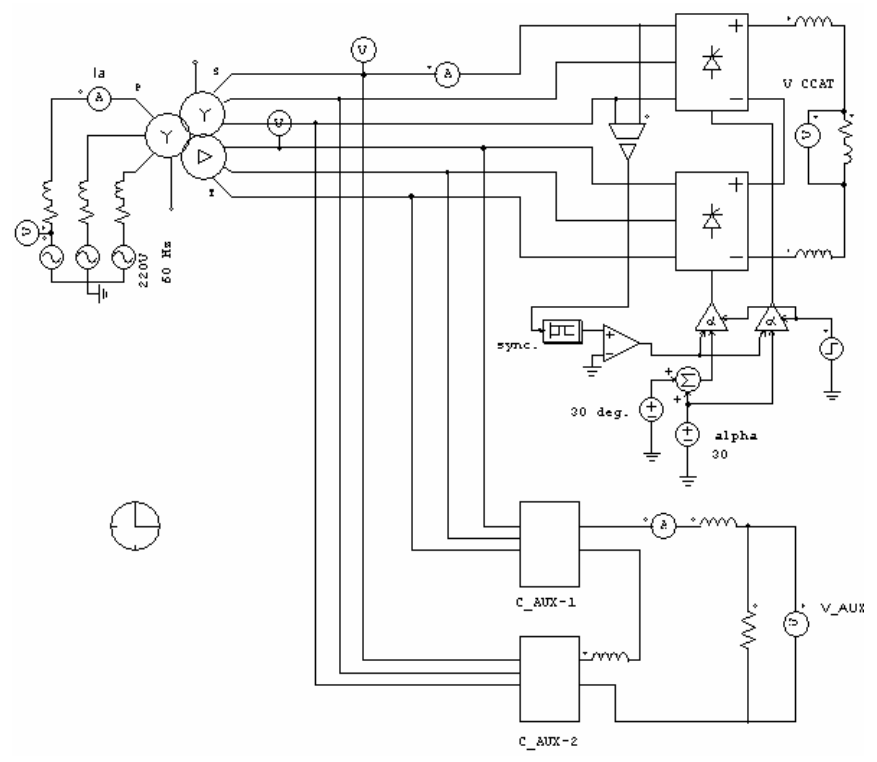

Fig. 2. Electrical schematics of the HVDC and auxiliary converters.

Another very important point to improve the current waveform is the current matching between the current level given by the extinction angle of the auxiliary converter and the beginning of the conducting phase in the main converter, so as to make both work as complimentary converters. As a consequence, the resulting current seen by the AC system tends to a sinusoidal form, as illustrates Figure 1. That improvement can be appreciated by comparing the resulting current waveforms with the ideal $\mathrm{AC}$ voltage for the resistive case.

\section{DESCRIPTION OF THE AUXILIARY CONVERTER}

The auxiliary converter used in this project is a reinforced IGBT 12-pulse switched converter. The function of the auxiliary converter is a current conduction path during the idle periods to approximate the AC current waveform to the AC voltage wave form.
In Figure 3 it can seen the schematic of one six-pulse IGBT bridge. The association in series of the two blocks of this bridge forms a 12-pulse auxiliary converter as depicted in Figure 2, the firing and blocking pulses of one bridge must also have a 30 degrees shift from each other. The overall interconnection schematic of the HVDC converter and auxiliary converter is also shown in Figure 2.

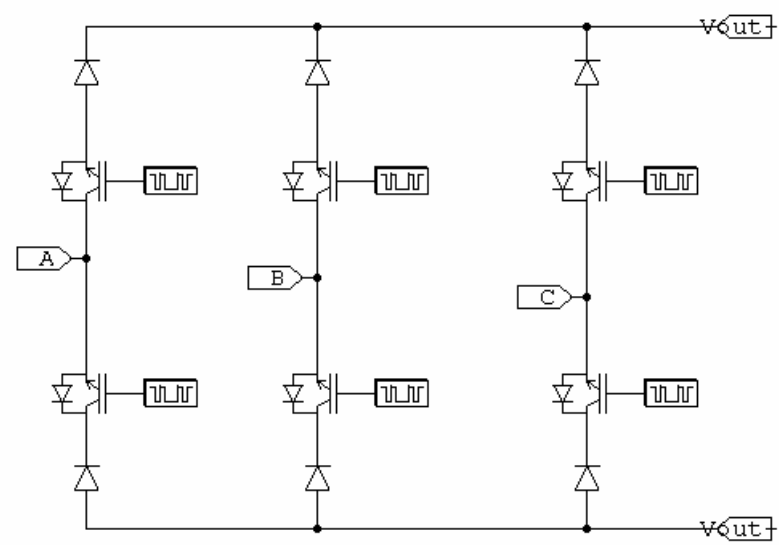

Fig. 3. Electrical schematic of one auxiliary converter bridge.

In quantitative terms, the DC output voltage of the auxiliary converter is the voltage during the HVDC converter idle periods defined as:

$$
V_{d c}=\frac{12}{2 \pi} \int_{0}^{\frac{\pi}{6}+\alpha} V_{m} \cdot \operatorname{sen}(\theta) \cdot d \theta
$$

whose solution gives:

$$
V_{d c}=\frac{6 V_{m}}{\pi}[1-\cos (30+\alpha)]
$$

To avoid current overlaps, the conduction period in the auxiliary converter is interrupted before the respective HVDC converter valve is reactivated. This small dead time corresponds to an angle $(\delta)$ considered in the following equations:

$$
\begin{aligned}
V_{d c}= & \frac{12}{2 \pi} \int_{0}^{\frac{\pi}{6}+\alpha} V_{m} \cdot \operatorname{sen}(\theta) \cdot d \theta \\
& -\frac{12}{2 \pi} \int_{\frac{\pi}{6}+\alpha-\delta}^{\frac{\pi}{6}+\alpha} V_{m} \cdot \operatorname{sen}(\theta) \cdot d \theta \\
V_{d c}= & \frac{6 V_{m}}{\pi}[1-\cos (30+\alpha-\delta)]
\end{aligned}
$$

For a purely resistive load the DC current is defined as:

$$
I_{d c}=\frac{6 V_{m}}{R . \pi}[1-\cos (30+\alpha-\delta)]
$$


So, the DC power is given by:

$$
P_{d c}=\frac{36}{R} \cdot \frac{V_{m}^{2}}{\pi^{2}}[1-\cos (30+\alpha-\delta)]^{2}
$$

This available output power capacity can be used to supply auxiliary loads, for energy re-injection in the AC line, and/or to produce hydrogen and oxygen through electrolysis of water.

In the $\mathrm{AC}$ side current there is a combination of the HVDC converter current and the auxiliary converter current so producing a practically sinusoidal line current and high (almost unity) power factor.

\section{PARAMETERS OF QUALITY}

For the purposes of this work, the following usual parameters were used to define the quality indexes:

\section{A. Total Harmonic Distortion (THD)}

THD expresses the total harmonic distortion [2] of a current or voltage signal and may be defined as:

$$
\begin{array}{r}
T H D=\frac{\psi_{h}}{\psi_{1}} \\
T H D=\sqrt{\frac{\psi_{r m s}^{2}-\psi_{1}^{2}}{\psi_{1}^{2}}}
\end{array}
$$

where:

$$
\begin{aligned}
& \psi_{1}=\text { effective value of the fundamental component of } \\
& \text { voltage or current } \\
& \psi_{h}=\text { RMS value including harmonic components and } \\
& \text { average value but excluding fundamental } \\
& \text { component } \\
& \psi_{r m s}=\text { total RMS value including all components }
\end{aligned}
$$

\section{B. Power Factor}

In usual systems of alternating sinusoidal current, the power factor $[2,3,4]$ is given by the cosine of the displacement angle between voltage and current. Since in converter circuits the current is not sinusoidal, the power factor cannot be defined as described above. So, the following expression is used:

$$
P F=\frac{V_{1} \cdot I_{1} \cdot \cos \left(\theta_{1}\right)}{V_{r m s} \cdot I_{r m s}}
$$

where:

$$
\begin{aligned}
& P F=\text { power factor } \\
& V_{r m s}=\text { line voltage RMS } \\
& I_{r m s}=\text { line current RMS }
\end{aligned}
$$

From the definition of THD given by (7), it comes:

$$
\frac{V_{r m s}}{V_{1}}=\sqrt{T H D_{v}^{2}+1}
$$

$$
\frac{I_{r m s}}{I_{1}}=\sqrt{T H D_{i}^{2}+1}
$$

to get from (8), approximately:

where:

$$
P F \cong \frac{\cos \left(\theta_{1}\right)}{\sqrt{\left(T H D_{v}^{2}+1\right) \cdot\left(T H D_{i}^{2}+1\right)}}
$$

$T H D_{v}=$ total harmonic distortion of the voltage

$T H D_{i}=$ total harmonic distortion of the current

$\theta_{1}=$ fundamental displacement angle.

\section{Efficiency $\left(\eta_{c}\right)$}

For the purposes of this paper, efficiency is defined as the relationship between the power supplied to the load connected to this equipment and the power delivered by the energy source to this load [2,3]. In the case of HVDC converters, the efficiency is the DC output power divided by the AC input active power.

$$
\eta_{c}=\frac{P_{d c}}{P_{a c}}
$$

\section{Utilization Factor}

The utilization factor is defined as the average power divided by the RMS power (effective voltage multiplied by the effective current) of the transformer secondary winding capacity [9].

$$
U F=\frac{P_{d c}}{P_{r m s}}
$$

\section{PRACTICAL RESULTS}

The results presented below were obtained either from simulation in software (PSim, SIMCAD) or in a CEEMA $2 \mathrm{~kW}$ prototype of 12-pulse conventional converter lab operation. The comparative figures used to define the levels of quality where the THD, PF, reverse-use of power in the auxiliary converter, UF and $\eta$. Such results were obtained from a set up of 12-pulse conventional converter and from a HVDC converter plus the main auxiliary converter. The circuit layout used in PSim simulations and practical tests is the same one shown in Figure 2. The practical results data were obtained through a Tektronics oscilloscope (TDS 1012) and a Fluke power quality analyzer (model 434).

To emphasize the effects of the auxiliary converter on the main converter parameters of interest, simulations and practical tests were carried out in a conventional 12-pulse HVDC converter without the conventional harmonic filters. From the results of these tests a reduction of power dissipation can be expected in each filter since they will absorb lower harmonic content from the main converter. However, simulations adding the harmonic filters to the main converter would provide an overall behavior of the converter group in a situation much closer to reality. 
The simulated voltage waveforms across the output of auxiliary converter for a $\alpha=15^{\circ}$ can be seen in Figure 4, and similar practical lab waveform is shown in Figure 5.

In Figure 6, the (V) line represents one phase voltages and the (I) line represents the HVDC converter current for a case without the auxiliary converter (woac). In Figure 7, the (V) line represents one phase voltage and the (I) line shows the total current through the HVDC in parallel with the auxiliary converter (wac) for $\alpha=30^{\circ}$.

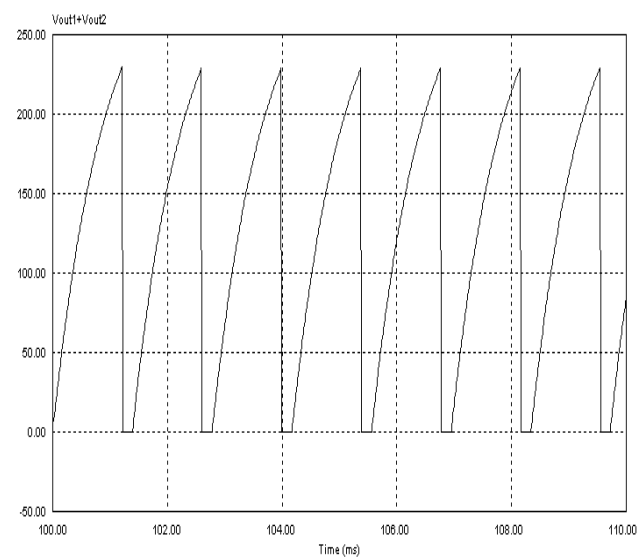

Fig. 4. Voltage waveforms across the auxiliary converter terminals (simulated outputs).

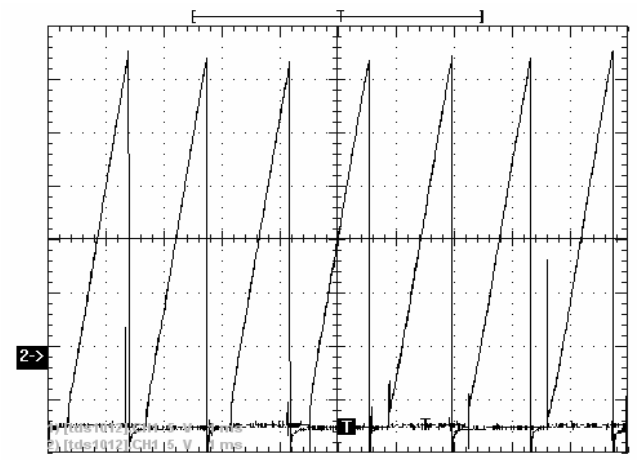

Fig. 5. Voltage waveforms across the auxiliary converter terminals (measured outputs)

Figure 8 illustrates the dynamic behavior of the HVDC converter with $\alpha$ varying from $30^{\circ}$ to $0^{\circ}$. In this figure the ( $\alpha$ ) line is $\alpha$, the (V) line represents the "a" phase voltage, the (I) line represents current through the HVDC converter. This figure can be compared to Figure 9 where the waveforms are of a HVDC converter in parallel with the auxiliary converter. In Figure 9 the $(\alpha)$ line is again $\alpha$, the (V) line represents voltage and the (I) line shows the total current through the converters, in both figures all waveforms represent the phase "a" variables. In Figure 9 is the phase "a" current is smoother (lower THD) and it is noticeable the reduction of PF. Also, there is not any current overlapping for all values of $\alpha$.

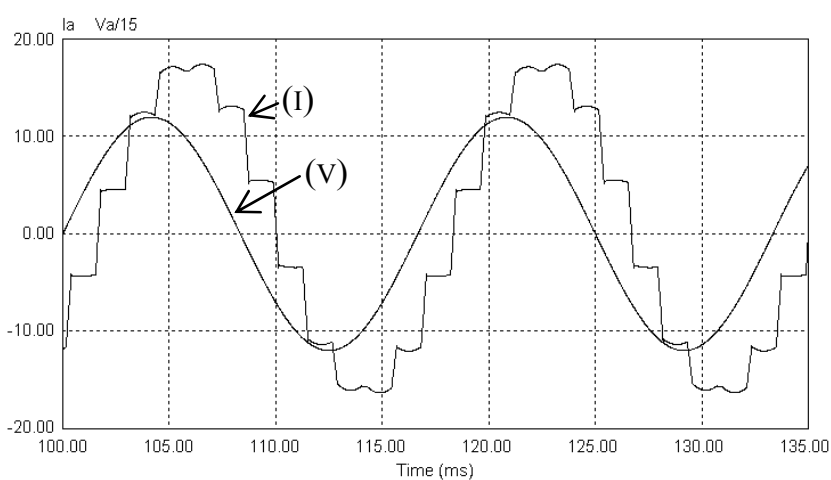

Fig. 6. Waveforms of phase "a" voltage across and current through of the HVDC converter without the auxiliary converter (simulated outputs).

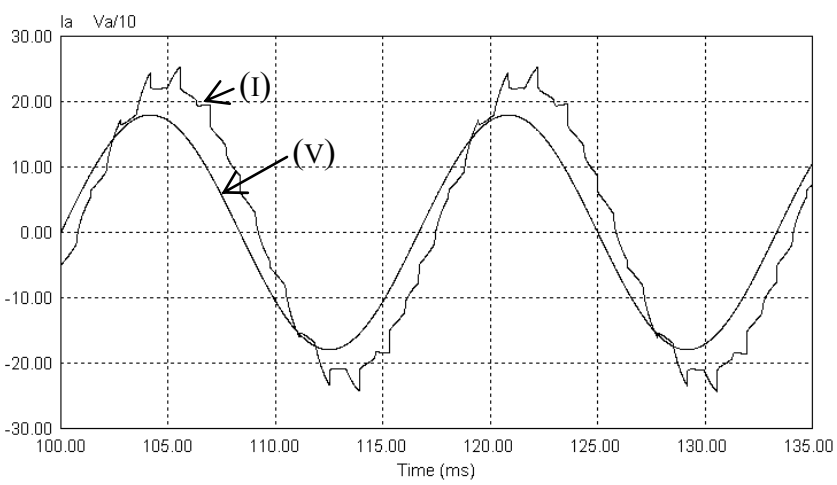

Fig. 7. Voltage across and total current through phase "a" waveforms with the auxiliary converter (simulated outputs).

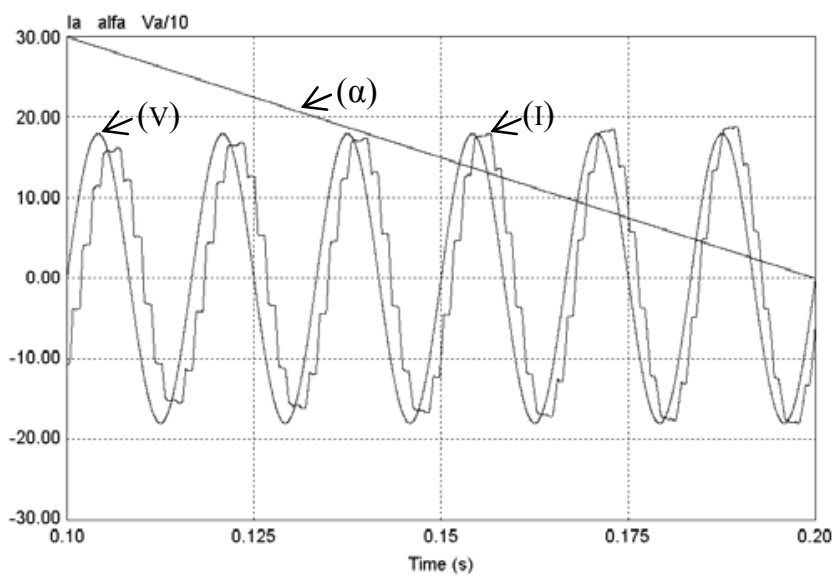

Fig. 8. Voltage across and total current through phase "a" with $\alpha$ variation from $30^{\circ}$ to $0^{\circ}$ without auxiliary converter (simulated outputs).

In lab practical tests the addition of the auxiliary converter decreases distortions on the AC line current waveform. This effect can be seen when comparing Figure 10 and Figure 11. The Figure 10 displays the traditional HVDC AC current and the Figure 11 shows the resulting composed current drawn by the HVDC plus auxiliary converters. 


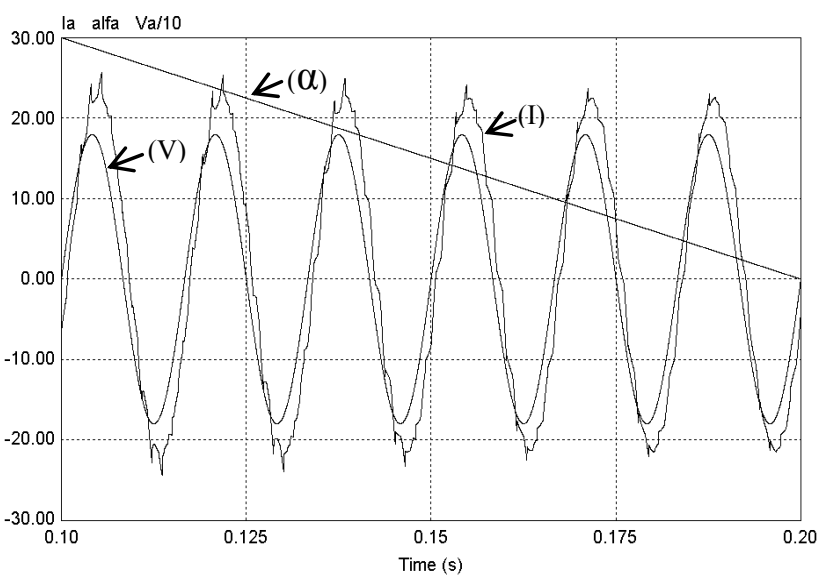

Fig. 9. Voltage across and total current through phase "a" with $\alpha$ variation from $30^{\circ}$ to $0^{\circ}$ with auxiliary converter (simulated outputs).

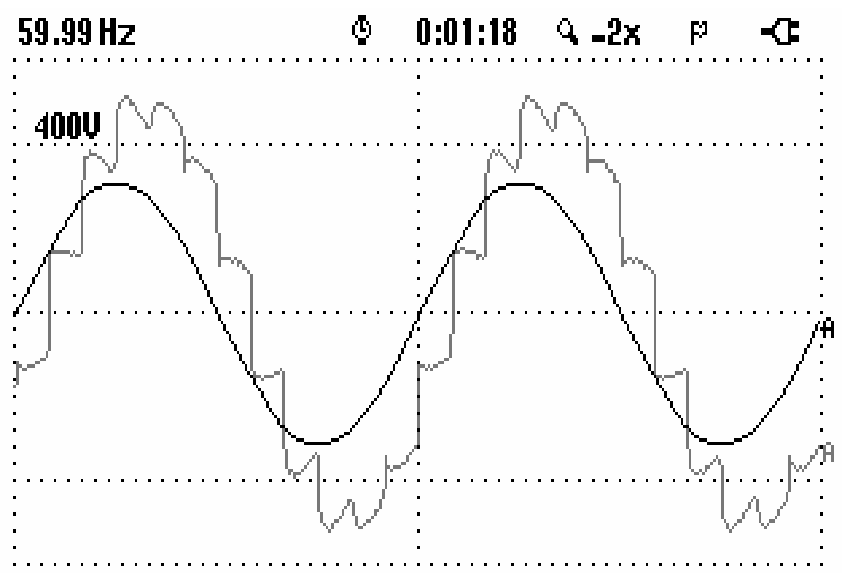

Fig. 10. Current through the HVDC converter terminals (measured outputs).

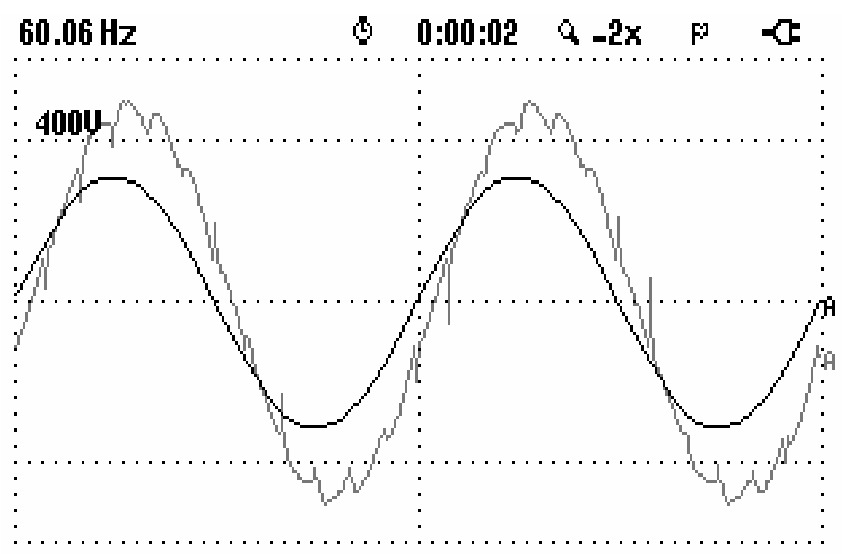

Fig. 11. Current through the HVDC converter plus auxiliary converter terminals (measured outputs).

Overall results were obtained in the simulated and practical tests as follows.

\section{A. Total Harmonic Distortion (THD)}

In order to estimate the total harmonic content, a PSim ready-made block called THD control was used. This block returns the THD value and the fundamental waveform. Figure 12 displays the spectral analysis of the HVDC AC current only, without the auxiliary converter, and Figure 13 includes the effects of the auxiliary converter.

Practical results of spectral analysis on the AC HVDC current without the auxiliary converter are shown in Figure 14. In Figure 15 the spectral analysis of the HVDC plus auxiliary converter AC current is shown. Comparatively, Figure 16 shows the simulated results with respect to the practical results of Figure 17. It is significant the reduction in the 11th and 13th harmonics, either of the practical and simulated results, in the order of $50 \%$. It is very clear here the drastic decrease in the harmonic content as the firing angle increases.

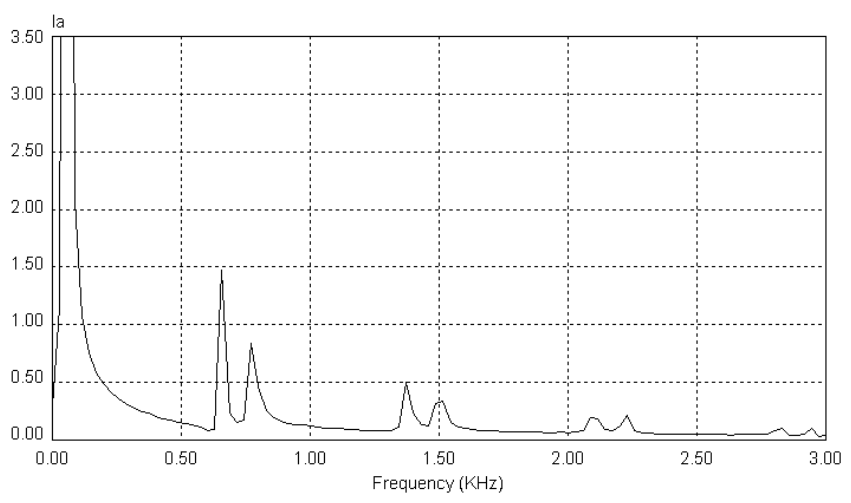

Fig. 12. Simulated spectrum of the AC current without auxiliary converter $\left(\alpha=25^{\circ}\right)$.

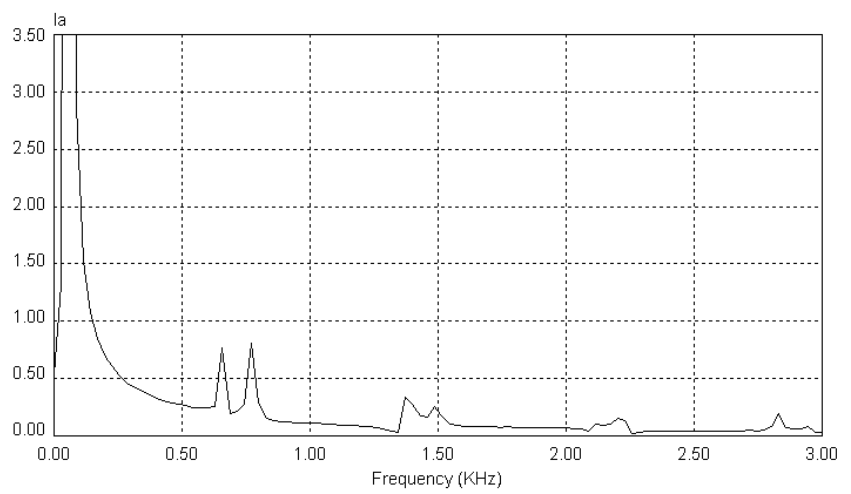

Fig. 13. Simulated spectrum of the overall AC current with the auxiliary converter $\left(\alpha=25^{\circ}\right)$.

\section{B. Power Factor}

Each converter power factor and whole group power factor were calculated again by the PSim measuring blocks known as RMS AC current and RMS AC voltage, either across the AC and DC sides and the AC power meters. From the resulting PSim simulation graphs, using the facility "Measure", the necessary values of voltage, current and power were obtained so that calculations were made in an EXCEL spreadsheet. Comparative results for several firing angles can be seen from the simulated graphs in Figure 18 and the practical graphs shown in Figure 19. Once more, it is evident the reduction in the power factor as 
the firing angle increases. In the case with $\alpha=25^{\circ}$ the simulated results shown an increase of the power factor from 0.880 to 0.975 , much similar to what was obtained in the practical measurements (an increase from 0.890 to 0.970).

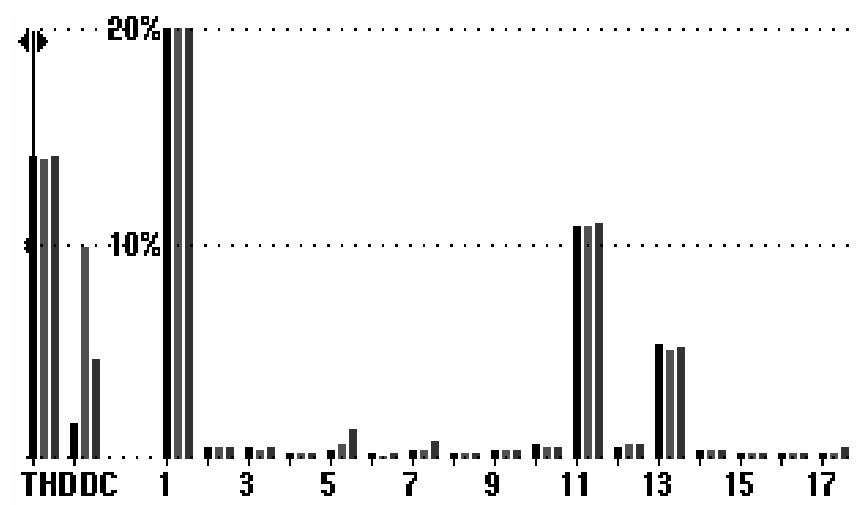

Fig. 14. Measured spectrum of the AC current through the HVDC converter terminals without auxiliary converter $\left(\alpha=25^{\circ}\right)$.

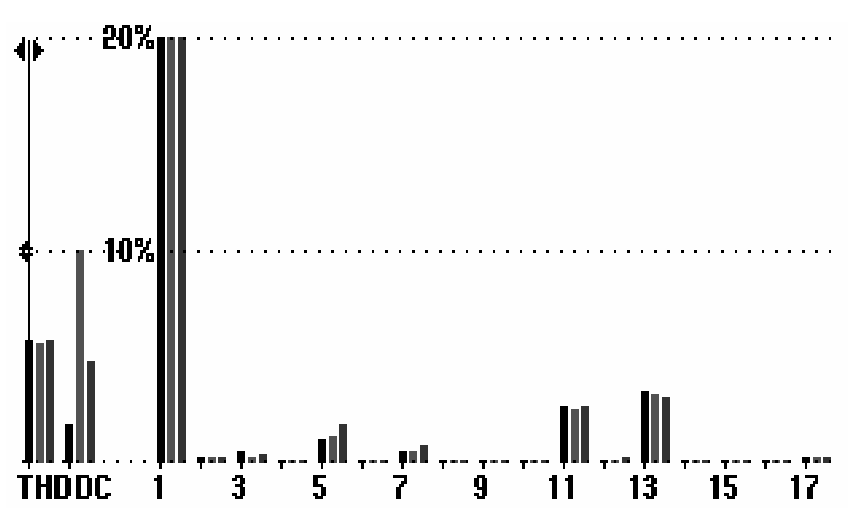

Fig. 15. Measured spectral analysis of the overall AC current including the auxiliary converter $\left(\alpha=25^{\circ}\right)$.

\section{Efficiency $(\eta)$}

As in the case of the power factor, the efficiency of each converter and group were calculated using the RMS AC current and RMS voltage meter blocks, either in the $\mathrm{AC}$ and $\mathrm{DC}$ sides and AC power meters. Efficiency of the main HVDC converter is not significantly affected by inclusion of the auxiliary converter operation. Efficiency of the auxiliary converter will depend on its switching mode and it is subject of next paper about this subject.

\section{Utilization Factor (UF)}

Once the values of the total DC power and apparent power were calculated through Equation (11), an utilization factor of $78.6 \%$ was obtained for the case without the auxiliary converter and of $94.5 \%$ for the case with the auxiliary converter, for maximum $\alpha$ of $30^{\circ}$. A high value of UF was confirmed whenever the auxiliary converter was used

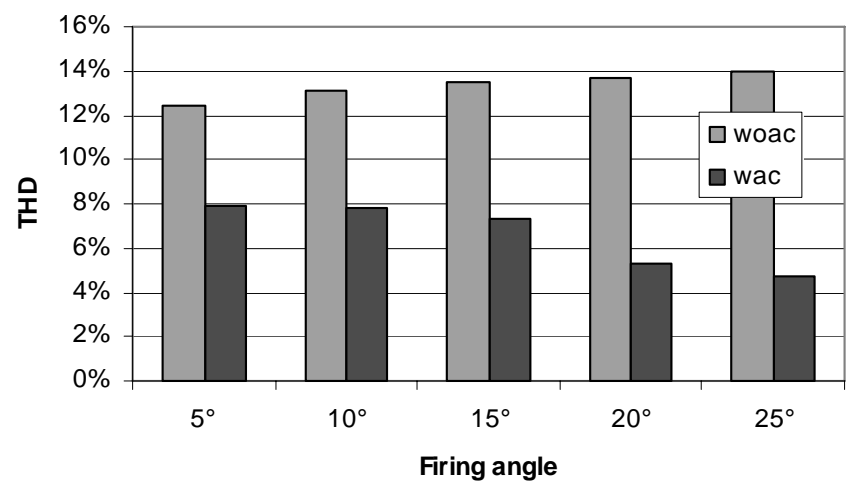

Fig. 16. Comparison between the simulated AC-side THD without and with the auxiliary converter.

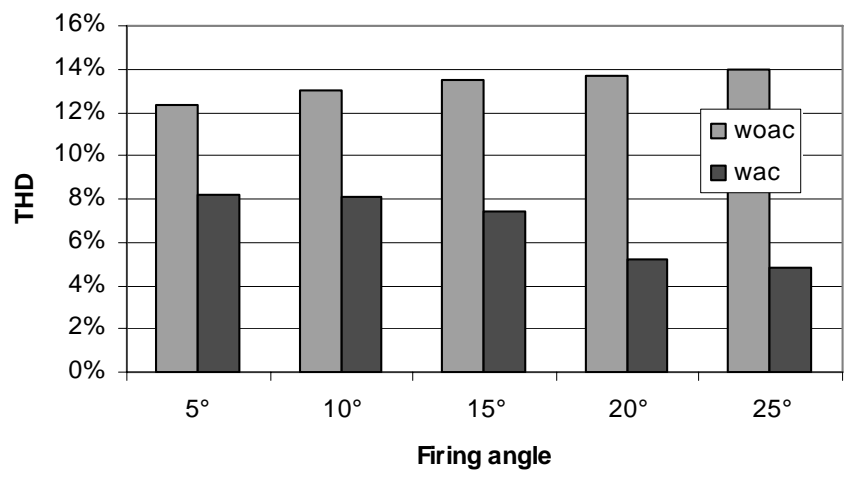

Fig. 17. Comparison between the practical AC-side THD without and with the auxiliary converter.

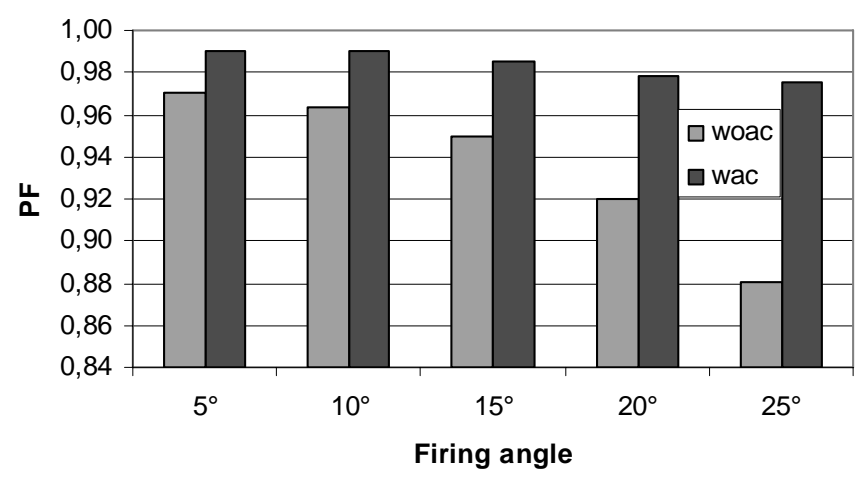

Fig. 18. Simulated PF as defined in Equation (10).

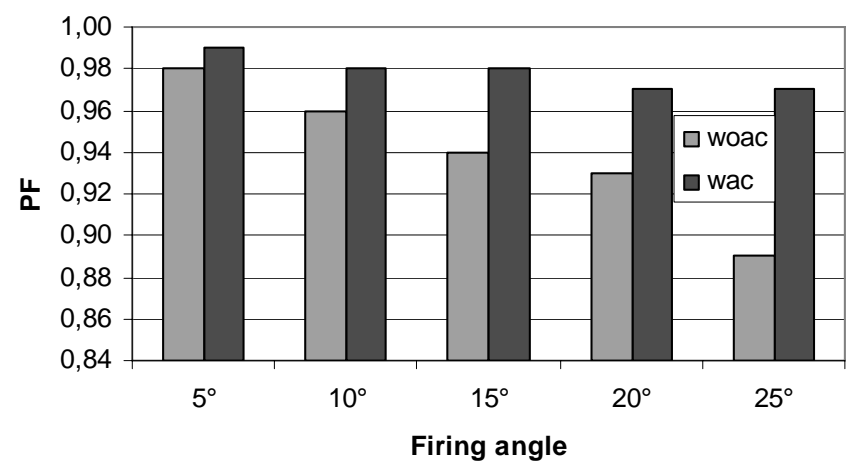

Fig. 19. Practical PF as defined in Equation [10]. 


\section{CONCLUSIONS}

Use of an auxiliary converter connected in parallel with a HVDC converter with phase control can be considered an important means for reverse-use of the idle periods energy capacity of HVDC converters. Also, addition of an auxiliary converter can minimize costs and improve the power quality indexes of HVDC transmission systems.

As most of the present HVDC converters operate with small firing angles, something between $2^{\circ}$ and $20^{\circ}$, they are exactly the most favorable angles for small capacity auxiliary converters since they will have to manage only low powers. This paper shows how the technique here proposed may get: a power factor closer to the unit, high operational efficiency, lower levels of THD, reduced intervention needs of the harmonic filters and utilization factors higher than $50 \%$ for transformers and semiconductors in the arms of the converter.

The use of an auxiliary converter in parallel with the conventional HVDC thyristor converter may advantageously improve quality of the transmitted electric power under the following aspects: 1 ) reduction in the THD values in all firing angles and especially up to $50 \%$ for larger firing angles; 2) in many cases, power factors as high as 0.90 can be obtained in the AC source without use of additional power filters, and above 0.95 with filters, for small and large firing angles; 3) efficiency of the main converter is practically unaffected justifying the fact that the addition of an auxiliary converter does not disturb the main converter operation; 4) possibility of reverse-use of the energy from harmonic distortions; 5) the example of utilization factor in this paper goes up to $78,6 \%$, working without auxiliary converter, and $94.5 \%$ with the auxiliary converter, considering a maximum $\alpha$ of $30^{\circ}$.

\section{ACKNOWLEDGEMENTS}

The authors are very thankful to CAPES-Brazil for their financial support and to the Post-Graduation Program in Electrical Engineering (PPGEE), Center of Research and Development in Electrical Engineering (NUPEDEE), and Center of Studies in Energy and Environment (CEEMA) of the Federal University of Santa Maria (UFSM). Special thanks to Mr. Jordan Trapp for his contributions along the development of this project.

\section{REFERENCES}

[1] A. Ghosh, G. Ledwich, "Power Quality Enhancement Using Custom Power Devices", Kluwer Academic Publishers, Boston, USA, 2002.

[2] A. M. Trzynadlowski, "Introduction to Modern Power Electronics", John Wiley \& Sons, USA, 1998.

[3] F. A. Farret, J. B. Parizzi, M. D. Zancan, "Simultaneous THD Minimization and Increased Power and Utilization Factors in HVDC Converters Using Auxiliary Converters", VI INDUSCON, Joinville, SC, Brazil, 2004.

[4] G. W Chang, S. Y. Chu, H. L. Wang, "A New Approach for Placement of Single-Tuned Passive
Harmonic Filters in a Power System", Power Engineering Society Summer Meeting, IEEE, vol. 2, pp.814-817, 2002.

[5] G. N. Bathusrt, N. R. Watson, J. Arrillaga, "A Comparison of Converter Models for the Derivation of the AC System Harmonic Impedances", IEEE Transactions on Power Systems, vol. 17, Issue 4, pp. 937-942, 2002.

[6] G. N. Bathusrt, N. R. Watson, J. Arrillaga, A. R. Wood, "Advanced Modeling of Harmonic Impedances of ACDC Converters", IEE Transactions, vol. 149, no. 6, 2002.

[7] H. Jou, L. Wu, K. D. Wu, "Parallel Operation of Passive Filter and Hybrid Power Filter for Harmonic Suppression", IEE Transactions, vol. 148, no. 1, 2001.

[8] R. Yacamini, J. W. Resende, "Harmonic Generator by HVDC Schemes Involving Converters and Static VAr Compensator", IEE Transactions, vol. 143, no. 1, 1996.

[9] F. A. Farret, L. L. Freris, "Minimization of Uncharacteristic Harmonics in HVDC Converters Through Firing Angle Modulation", IEE Transactions, vol. 137 , no. $1,1990$.

[10] J. R. Gomes, F. A. Farret, M. Pieniz, "Harmonic Minimization in HVDC Systems Through Multiple Injection of Supplementary Control Signals", 28th Annual Conference of the IEEE Industrial Electronics Society, IECON 02, Spain, 2002.

[11] Y. H. Liu, J. Arrillaga, N. R Watson, “A New HighPulse Voltage-Sourced Converter for HVDC Transmission", IEEE Transactions on Power Delivery, vol. 18, Issue: 4, pp. 1388-1393, Oct. 2003.

[12] G. W. Chang, W. Hung-Lu, C. Shou-Yung, "Strategic Placement and Sizing of Passive Filters in a Power System for Controlling Voltage Distortion", IEEE Transactions on Power Delivery, vol. 19, Issue 3, pp. 1204-1211, July 2004.

\section{BIOGRAPHIES}

Jocemar B. Parizzi received his B.E. in Electrical Engineering from the Federal University of Santa Maria in 2003. He is Ph.D. student of the Post-Graduation Program in Electrical Engineering of the Federal University of Santa Maria. He was instructor at the Industrial Technique School of the Federal University of Santa Maria, Brazil, committed to under graduation studies in 2005.

In more recent years, has been working in any projects about renewable sources of energy coordinated by Dr Farret; low power PEM fuel cell application, injection of electrical power into the grid, HVDC transmission energy quality, ac-ac and ac-dc-ac links and hydrogen generation is currently his major interest.

Felix A. Farret received his B.E. and M.Sc. in Electrical Engineering from the Federal University of Santa Maria in 1972 and 1986, respectively; specialist in instrumentation and automation by the Osaka Prefectural Industrial Research Institute, Japan; M.Sc. by the University of Manchester, UK in 1981 and Ph.D. from the University of London, UK, in 1984 all in Electrical Engineering. He was 
operation and maintenance engineer for the State Company of Electrical Energy (CEEE) in the RGS state 1973-1974, Brazil. He has been working in an interdisciplinary educational background related to power systems, power electronics, nonlinear controls and integration of renewable energies. He teaches at the Department of Electronics and Computation of the Federal University of Santa Maria, Brazil, committed to under-graduated and graduated activities and in research developments, since 1974 . He was a visiting professor at Colorado School of Mines, Engineering Division, USA 2002-2003. He has published his first book in Portuguese Language titled Use of Small Sources of Electrical
Energy (UFSM University Press, 1999), co-authored the book Renewable Energy Systems: Design and Analysis with Induction Generators (CRC Press, 2004) and authored the book Integration of Alternative Sources of Energy (John Wiley \& Sons, 2006). Energy Engineering Systems is the focus of his present interests for distribution and industrial applications.

Álvaro B. Serdotte is currently graduate student of the Electrical Engineering Course in the Federal University of Santa Maria and engaged in projects of alternative sources of energy. 